\title{
Study on the Current Situation and Crux of Calligraphy Education in Yunnan Colleges and Universities
}

\author{
Yaping Yang ${ }^{1, *}$ \\ ${ }^{1}$ Baoshan University, Baoshan, Yunnan 678000, China \\ *Corresponding author. Email: yangyapingyn@163.com

\begin{abstract}
On the basis that the calligraphy education in colleges and universities in Yunnan Province starts late, the concepts are antiquated, the teaching methods lag behind, the calligraphy resources are lacking, and the calligraphy education is underestimated, this article starts from positivity, comprehensiveness, optimality, foreseeability and practicalness, reflects on the crux of calligraphy education in colleges and universities, and explores the special laws of calligraphy education in colleges and universities in Yunnan Province, so as to unify knowledge and skills as well as culture and aesthetic education in higher education, improve and promote the depth and level of calligraphy education, promote the reform of calligraphy education in colleges and universities, and find the best way, best method, and best model for calligraphy education in colleges and universities in Yunnan Province.
\end{abstract}

Keywords: Yunnan, Colleges and universities, Calligraphy education, Current situation, Crux.

\section{INTRODUCTION}

As the borderland of the southwest, Yunnan is rich in national culture, history and local conditions and customs. With the development of social economy and the support of educational policies, the development scale of colleges and universities in Yunnan Province has continued to expand, and the speed of transformation and development has also increased dramatically. However, how to take root in the local area, keep a foothold in Yunnan, serve the frontiers, and keep up with the pace of the times in order to do a good job in the construction of calligraphy education and the inheritance of calligraphy culture in colleges and universities in Yunnan Province is the challenge faced by people.

\section{WEAK TEACHER RESOURCES}

Compared with other big and powerful fraternal cultural provinces, Yunnan Province has a smaller teaching staff of colleges and universities and

*Fund: This article is the result of the "Research on Calligraphy Education in Colleges and Universities in Yunnan Province" project from the Scientific Research Fund of the Department of Education of Yunnan Province, No.: 2019J0335 relatively weak teacher resources. There are historical reasons, and there are also subjective factors that Yunnan Province doesn't pay enough attention to the subject of calligraphy. Compared with subjects such as music and dance, it is an indisputable fact that Yunnan Province's calligraphy education lags behind colleges and universities in other provinces. Nowadays, there is a phenomenon of fault of teacher resources in Yunnan Province. On the one hand, the older generation of calligraphers retired, such as Professor Zhao Yirong of Kunming University and Professor Chen Hongling of Yunnan Arts University. On the other hand, there is a shortage of teachers in some newly-added calligraphy majors in some colleges and universities in Yunnan Province, so they can only temporarily hire some fine arts teachers or teachers from off-campus institutions to teach. These teachers who have not been professionally trained are often unable to systematically teach. They just "fragment" the system or merely lead the calligraphy profession to technical training. Of course, a heartening situation is that there are still a few talents like Dr. Cheng Lianfang from Yunnan University in Yunnan 
Province. These people are highly educated in literature, history, philosophy, etc., and they are both excellent in professional skills and morality. It's believed that under their guidance, the calligraphy education in Yunnan Province will definitely rise from the valley bottom, and it is only a matter of time before it is ahead of other fraternal provinces, so people here should not be pessimistic.

A small part of the teaching faculty of calligraphy education in Yunnan colleges and universities are teachers who graduated from excellent calligraphy specialized institutions in China, and those with strong ability are the best among the young and middle-aged teachers. But the most prominent thing is that, on the one hand, calligraphy education is facing the retirement of outstanding literary and art educators, and there is still a gap in literary background between the new teachers who are professionals by training. On the other hand, teachers majoring in fine arts or those who love calligraphy undertake the teaching of calligraphy courses.

\section{THE TRAINING GOAL IS NOT CLEAR}

There are eight colleges and universities in Yunnan Province that recruit students majoring in calligraphy. These colleges and universities can be roughly divided into three categories: normal category, art category, and comprehensive category. Normal colleges and universities include Yunnan Normal University, Qujing Normal University, Chuxiong Normal University, Zhaotong University, and Yuxi Normal University. Art colleges and universities include Yunnan Arts University, and comprehensive colleges and universities include Yunnan University and Dali University. The author believes that the training objectives of normal colleges and universities should be closely related to the future professional needs of students. The curriculum structure and credit settings in the professional talent training program are not quite reasonable, and the goal of closely integrating calligraphy basic education is not clear, that is, how to be a qualified calligraphy teacher in primary and secondary schools. How do these students offer technique courses? Since the calligraphy class of primary and secondary school students focuses on interest and enlightenment, the focus of technique learning should be on the standardized form of Chinese characters, that is, regular script and clerical script technique training. In addition to technique teaching, a course related to "calligraphy teaching method" should be offered at the same time, and this course currently has no ready-made textbooks in China, which requires teachers to devote themselves to research and development. This process involves some interdisciplinary subjects such as pedagogy, psychology and other related subjects.

As for the training goals of art colleges and universities, the author thinks that its focus should be on techniques and creation. To achieve the "five calligraphy styles" concurrently, according to the actual situation of the individual, from the junior year, students should be asked to establish the main direction of study, study the brushwork, method of the use of ink and water, the form composition, as well as the selection and use of materials (writing brushes, ink sticks, paper and inkstones) and other issues of these calligraphy styles.

The training objectives of comprehensive colleges and universities should focus on research. Students should learn the methods and ways of learning, and engage in scholarship independently in the process of learning, putting techniques in a slightly less important position. Only by clarifying the training objectives of various colleges and universities can it be possible to allocate educational resources in a targeted and reasonable manner, for example, teachers should be assigned according to speciality, and the best material should be used at the key point. Conversely, going about several tasks at a time will make it difficult to cultivate high-quality talents, and it is not conducive to the development of calligraphy education in Yunnan Province in the long run.

\section{THE TEACHING METHOD IS LAGGING BEHIND}

\subsection{Unbalanced Curriculum Provision}

Calligraphy is a discipline based on the discipline of art, and the history of art development is a history of art criticism. Judging from the current situation, the problems of uneven development of calligraphy history, calligraphy techniques, and calligraphy criticism are common in colleges and universities that offer calligraphy majors. Colleges and universities that focus on the teaching of history and techniques emphasize the study of ancient theory of calligraphy, lack the discussion of modern theory of calligraphy, and ignore calligraphy criticism, especially contemporary calligraphy criticism. As everyone knows, the study of calligraphy theory courses is 
difficult. Colleges and universities can guide students to pay attention to major exhibitions and competitions related to the current calligraphy, pay attention to the discussion and criticism of the content, form, and technique of the works, and comment on the works of contemporary calligraphers, which will surely stimulate students' interest in learning and will be a good breakthrough for learning calligraphy theory courses. Therefore, in the setting of the curriculum, calligraphy theory should be balanced with calligraphy criticism, and ancient calligraphy criticism should be balanced with modern and contemporary calligraphy criticism. Only in this way can the theories of the predecessors be tested; only in this way can the position of contemporary calligraphy in the history of calligraphy be accurately judged; and only in this way the excellent historical theories of calligraphy in ancient China be developed and inherited.

At the same time, the philology courses offered by schools have few class hours and short cycles, leading to wrong seal or cursive methods when students write seal scripts and cursive scripts due to the unknown origin of the characters. Philology is the foundation of predecessors' learning. Looking at the whole country, this subject is the weak link countrywide. Colleges and universities can hire some scholars and experts to give lectures at the school, or they can send teachers out for training or follow-up study.

\subsection{The Degree of Curriculum Integration Is Not High}

In conventional teaching classrooms, teachers play a leading role and students passively accept learning. A single teaching mode can no longer satisfy students' curiosity about new things. A good teaching courseware should start from many subjects such as history, literature, philosophy, aesthetics, design, etc., and ingeniously design to stimulate students' interest in learning and improve students' aesthetic ability. This requires teachers to have higher cultural literacy and comprehensive ability.

Teachers should have different teaching design concepts for the teaching of different calligraphy styles. The process of learning calligraphy is the process of learning history. The emergence of each type of calligraphy in the brief history of calligraphy is closely related to the historical background of the time. Teachers can analyze the life and history of calligraphy in each historical period from the perspective of history. When appreciating and copying classic rubbings, the lines and columns of characters are full of intriguing and humanistic atmosphere. It involves verses, ditties, odes, songs, couplets, etc. Teachers can interpret the content of calligraphy from the perspective of philology. It can be said that the process of appreciating and copying is the process of students learning literary knowledge. Virtually, students have accumulated a wealth of literary knowledge and their literary level has been improved. In addition, teachers can analyze and judge the pros and cons of a calligraphy work from the perspective of aesthetics, so that the beautiful diction and the beautiful form of classic calligraphy can be organically combined. This exactly reflects $\mathrm{Mr}$. Ouyang Zhongshi's concise expounding of his understanding of calligraphy in sixteen characters, that is, the idea of "writing is for writing articles, writing articles is for expressing meaning, recording language and reflecting culture, and books are for making articles glow and satisfying needs".

At the same time, calligraphy can promote design subjects, such as graphic design, environmental design, advertising poster, and packaging design. Teachers can try to combine calligraphy and design teaching. For example, after each stage of practical learning of calligraphy style, teachers can ask students to design patterns in combination with professional directions; teachers can also combine traditional festivals and calligraphy in teaching. For example, during the Mid-Autumn Festival, students can choose to copy copybooks related to the Mid-Autumn Festival, such as Wang Xianzhi's "Zhong Qiu Tie", Mi Fu's "Zhong Qiu Deng Hai Dai Lou Zuo Shi Tie", and Zhao Zhiqian's "Zhong Qiu Shi Si Ping", and make it a greeting card to send to relatives and friends.

Undoubtedly, there is a close relationship between calligraphy and related subjects. This is a concentrated expression of the social function, educational function, and aesthetic function of calligraphy, and it also allows the comprehensive application of cultural knowledge of various subjects in the process of calligraphy teaching, thus arousing students' interest in learning calligraphy, guiding students to correctly understand the function and value of calligraphy, so as to achieve the purpose of cultivating students' artistic perception and innovative spirit. The integrated teaching of calligraphy and related subjects is also the embodiment of the combination of theory and practice in calligraphy classroom teaching. It allows students to effectively guide practical skills training 
while gaining the accumulation of theoretical knowledge, so as to achieve the true purpose of learning calligraphy, which is also the meaning of learning calligraphy.

\section{THE RANGE OF TARGET AUDIENCE IS NARROW}

Up to now, only 8 colleges and universities in Yunnan Province have established calligraphy majors. For other colleges and universities across the province, in some schools, calligraphy is offered as a major of fine arts, or as a school-wide public elective course or a required course for normal majors.

\subsection{The Setting-up Situation of Normal Majors}

Standardized character teaching is particularly important to consolidate the professional quality and professional skill education of students majoring in normal majors. The courses of "three strokes", "three-stroke training" or "standardizedcharacters teaching" are used as a basic course for the training of vocational skills in normal practical teaching projects. The vast majority of these courses offered by colleges and universities are conducted in accordance with two class hours per semester, which is far from meeting the needs of students' vocational education. This is only a kind of simple comprehensive theoretical knowledge and single technique training, only staying at the level of use and popularization.

\subsection{The Setting-up Situation of the Whole School}

Taking the comprehensive college where the author works as an example, so far, the school has established 15 secondary colleges with more than 10,000 students. In addition to the Gem Identification and Processing Major of the College of Jewelry, the specialized majors set up by the colleges are mainly teachers' education majors. Therefore, most colleges aim to improve the basic skills of students and teachers, combine the professional curriculum provision of teachers' education majors, and set up "Three Strokes" or "Three-Stroke Training" professional elective courses. According to the survey, the College of Humanities, the College of Education, the College of Art and Design, and the College of Jewelry all set up these courses as required courses for students in their majors. The name of the course offered by the College of Jewelry is "Introduction to Calligraphy and Paintings", and the course offered by the College of Art and Design is "Basic Calligraphy". The calligraphy-related courses offered by the above colleges are 38 class hours (set up for one semester) and 2 credits. For all undergraduate majors in the school, in addition to the "Basic Calligraphy" offered by the College of Art and Design for students majoring in fine arts, and the "Three-Stroke Training" course offered by the College of Humanities for students majoring in history, the only way for other students to obtain calligraphy classroom teaching is through the school-wide calligraphy elective courses offered by relevant calligraphy teachers to meet the needs of lovers. If calculated according to the proportion of public elective courses within 200 students in a semester, by the first semester of the junior year, nearly $3 / 4$ of the students in the school will not have access to the calligraphy elective course. It is understood that if a student who loves calligraphy fails to take the calligraphy elective course, he can expand his calligraphy hobby by joining the College Students' Calligraphy and Painting Association, but after all, this kind of participation is limited.

The above situation shows that there are many students who love calligraphy. However, due to the different professional settings of each college, the different positioning of talent training and the limited popularization of traditional Chinese calligraphy culture by the school, the coverage of students' learning and exposure to calligraphy is relatively small. According to statistics, the proportion of school-wide calligraphy-related elective courses in colleges and universities in Yunnan Province has not exceeded $40 \%$.

\section{CONCLUSION}

In summary, as a base for cultural inheritance and the main body of cultural innovation, colleges and universities should become leaders, planners and persons in charge in cultural inheritance and innovation, strive to build a spiritual temple to realize the beautiful expectations and value vision of the Chinese nation, and do a good job in the inheritance of traditional culture within schools. Therefore, it is the obligatory duty of calligraphy educators to build and inherit calligraphy education in colleges and universities in Yunnan Province in the university culture, so that it can face the contemporary era and go to the world. 


\section{AUTHORS' CONTRIBUTIONS}

This paper is independently completed by Yaping Yang.

\section{REFERENCES}

[1] Ouyang Zhongshi, ed, Calligraphy Tutorial, Beijing: Higher Education Press, 2011.8. (in Chinese)

[2] Yang Suoqiang, Exploration of Calligraphy Collection of Yang Suoqiang's Calligraphy, Shaanxi: Xi'an Jiaotong University Press, 2014.10. (in Chinese)

[3] Chen Longhai, ed, University Calligraphy Course, Beijing: Higher Education Press, 2019.10. (in Chinese)

[4] Zeng Chuanguo, University Calligraphy Course, Hunan: Central South University Press, 2018.9. (in Chinese)

[5] Ye Peigui. Calligraphy, Beijing: China Social Publishing House, 2009.10. (in Chinese)

[6] Huang Jianxin. University Calligraphy Course, Zhejiang: Zhejiang Ancient Books Publishing House, 2005.9. (in Chinese) 